\title{
Sobre o perecível
}

Julia Arbex ${ }^{1}$

Resumo: Uma diferente leitura para o conceito de perecível é proposta traçando-se uma aproximação ao que o filósofo francês Gilbert Simondon chamaria por sistema metaestável e como esse perecível poderia se materializar num trabalho de arte.

Palavras-chave: perecível, metaestável, equilíbrio, materialidade

\section{About the perishable}

Abstract: A different reading for the concept of perishable is proposed by drawing an approximation to what the French philosopher Gilbert Simondon would call a metastable system and how this perishable could materialize in a work of art.

Key words: perishable, metastable, equilibrium, materiality

“Tudo flui"i. Para onde? Não se sabe.

Uma das questões centrais para a cosmologia da Grécia Antiga - e que marca o início da filosofia ocidental - é a da constante mutação das coisas. Se há um problema que os gregos investigam, em especial os primeiros pensadores, é o da geração e da corrupção. Por que os seres nascem, se desenvolvem perecem e tornam a nascerii?

\footnotetext{
${ }^{1}$ Julia Arbex, 1982, Rio de Janeiro. Mestre em Estudos dos Processos Artísticos pela Universidade Federal Fluminense - UFF com a dissertação intitulada Divagações sobre o perecível. Em 2018 realizou a exposição Bruto na Galeria Portinari. Em 2017 participou das exposições "Responder a todos" (Despina, 2017) como a segunda parte de um projeto de colaboração entre artistas brasileiros e ingleses que teve sua primeira exposição na Manchester school of Art (Reply all, MSA UK, 2016); e "Pensar alegórico" (Ateliê Dezenove, 2017). Em 2014 foi selecionada para o Salão NOVÍSSIMOS (Galeria de Arte IBEU, 2014).
} 
Deve haver, concluíam eles, um substrato ou uma matéria originária que nem envelhece nem morre e a partir do qual tudo o mais se engendra e ao qual tudo o mais retorna.

$\mathrm{Na}$ origem do pensamento filosófico grego, a concepção de physis pode ser encontrada em intrínseca relação com a ideia de uma ordem imanente ou uma espécie de entendimento que permeia os movimentos e processos da natureza. 0 termo natureza, no entanto, se origina posteriormente de uma tradução latina para o termo grego physis em escritos do filósofo romano Sêneca, datados de $62^{\text {iii. }}$ Mas é preciso considerar que essa tradução não é totalmente equivalente, tendo sofrido, ao longo dos séculos, importantes transformações de significado. Mesmo entre os antigos, seu sentido varia e é controverso: é possível encontrar associação com a teoria atomista sobre a constituição das coisas, na Idade Média uma compreensão ambígua da natureza - ao mesmo tempo criada por Deus e inabitada por ele - e no século XVII a consolidação de um pensamento mecanicista. Pode-se dizer que a ideia comum de natureza é herdeira direta desta última concepção.

Segundo Marcia Gonçalvesiv, o início da especulação filosófica sobre o mundo é em grande parte acompanhado pela tradição mítica grega de unidade entre espírito e natureza, e, ao mesmo tempo, pelo início de certo estranhamento entre o ser humano pensante e o ser natural ou a totalidade dos demais seres da natureza, ou seja, a natureza em sua totalidade. Nas palavras da autora,

\footnotetext{
Essa concomitância de origem entre a filosofia da natureza e a filosofia em geral nos permite compreender que o fundamento da primeira é muito menos a física, entendida por uma rede de conceitos científicos empiricamente comprovados, e muito mais a ideia grega de physis enquanto totalidade substancial do mundo material. Essa concepção originária da natureza abre-se de imediato para uma dimensão frequentemente interpretada como metafísica, ou seja, que transcende a possibilidade de experimentação (GONÇALVES, 2006, p .7).
}

Aristóteles descreve esse estranhamento com exemplos de fenômenos cósmicos, tais como "as mudanças da lua" ou "aquelas relativas ao sol e às estrelas" ou os fenômenos decorrentes do que denominava "geração do universo". No entanto, cerca de 200 anos antes de Aristóteles, os pré-socráticos ou "physiólogos" postulam teses sobre a constituição do universo a partir de algum elemento primordial, uma 
substância originária da qual todas as coisas seriam constituídas. Tales elege a água, Anaximandro, o apéiron, Anaxímenes, o ar e Heráclito escolhe o fogo como a "causa material" ou o princípio a partir do qual tudo nasce e tudo perece.

Com Platão e Aristóteles, inicia-se o que pode ser chamado de tradição metafísica. Alguns dos pré-socráticos, como Parmênides e Heráclito, já apontam para isso, mas com Platão e Aristóteles a ruptura é definitiva. Etimologicamente, metafísica quer dizer além da física. 0 pensamento metafísico passa a buscar aquele substrato que os pré-socráticos tentavam encontrar em meio às coisas além do mundo físico. Platão, o inaugurador desta tradição, formula sua famosa teoria das ideias, que concebe um mundo de formas eternas do qual os entes do mundo físico seriam cópias. Já Aristóteles concebe a realidade a partir da oposição entre matéria e forma.

O pensamento contemporâneo, em geral, se volta para a tentativa de superar a metafísica dualista, que concebe um mundo fixo de verdades eternas separado daquele das mudanças. Essa foi a tarefa de filósofos como Nietzsche, Bergson e Merleau-Ponty. Nesse contexto, também se insere o filósofo francês Gilbert Simondonv . Inspirado pelo pensamento pré-socrático e por filósofos contemporâneos como Bergson, Simondon se dedica a pensar a realidade como processo, afastando-se do modelo da realidade estática.

Um conceito chave em Simondon é o conceito de individuação. 0 filósofo o formula em resposta à antiga questão filosófica que diz respeito ao modo como qualquer 'coisa' - um organismo animal, uma máquina, um objeto técnico, ou um ser humano - se torna o que é. Ou seja, como algo se constitui como indivíduovi.

Um dos alvos de Simondon é o que ele chama de pensamento hilemórfico. A doutrina do hilemorfismo, ideia que remonta à Artistóteles e à metafísica a partir de então sustenta que a formação de indivíduos aconteça a partir da junção de uma matéria (hilé, em grego) à uma forma (morphé). A gênese do indivíduo, deste modo, aconteceria através do encontro de uma forma pré-dada com uma matéria, também já existente. A forma, certo modelo ideal que pode ser repetido indefinidamente, representaria uma imposição, um triunfo sobre a matéria, já que a molda de acordo 
com seus próprios princípios. Este dualismo marca profundamente não só o pensamento, como a própria estética ocidental.

Para Simondon, na medida que um indivíduo existe, devem existir vários processos que façam com que ele se forme, se constitua. Forma e matéria não são suficientes para explicar a individuação. Há algo que escapa a estes dois domínios e ao qual o pensamento hilemórfico se mantem cego.

Simondon usa o tijolo - que já era exemplo para os antigos gregos da dicotomia forma e matéria - para discutir esse problema. 0 tijolo é composto de dois elementos diferentes: argila sem forma e o molde de fôrma. Para o hilemorfismo, a argila é considerada passiva em relação aos efeitos do molde que impõe do exterior uma forma para o tijolo.

Para Simondonvii, explicar a constituição de um tijolo vai muito além da simples equação forma + matéria. A ordem microfísica da argila deve estar alinhada com as forças macrofísicas do molde para que haja um tijolo que se sustente como matéria enformada; os materiais não são eles próprios crus, pois cada um já está preparado para sua 'tarefa'. O molde introduz uma maneira de organização na transformação da argila em um tijolo. Ou seja, na constituição do tijolo é necessário estar em jogo forças energéticas que perpassam os materiais, a fôrma, e a própria atividade da máquina e do trabalhador que a manuseia.

Perceber apenas a forma e a matéria nesse processo seria considerar apenas o antes e o depois, sem ter olhos para o processo dinâmico de sua constituição. Para captar o processo, deve-se recuar ao que Simondon denomina de estado pré-individual. “0 pré-individual não é matéria nem forma, e sim uma carga potencial”viii, uma energia que possibilita que ambos - forma e matéria - funcionem em uma crescente interrelação e que continue mudando.

A condição prévia da individuação, segundo Simondon, é a existência de um sistema metaestável. Para Elizabeth Grosz, o pré-indivíduo é o centro da concepção de ser de 
Simondon, mas não um ser composto de identidades, coisas, substâncias e sim uma ordem metaestável da qual os seres, ou melhor, os devires, se engendram.

O metaestável não é um estado de equilíbrio nem um estado de esgotamento, mas encontra-se em uma condição de tensão e potencialidade. Nem é estável nem instável, trata-se de um estado sujeito a mutação, transformação.

O sistema metaestável é dinâmico, contém energia e informação. A partir de um disparo ele é capaz de produzir uma interação onde previamente não existia uma comunicação interativa, e essa interação possibilita a troca entre energia e informação. Nelson Brissac Peixoto acrescenta que

\begin{abstract}
um sistema físico está em equilíbrio "metaestável" quando certas variações podem levar a uma ruptura do equilíbrio. Essa ruptura é possível porque os elementos do sistema estão em tensão permanente. Essa tensão engendra potenciais que podem produzir uma brusca alteração, conduzindo a uma nova estruturação igualmente metaestável (PEIXOTO, 2010, p. 19).
\end{abstract}

Sendo assim, a metaestabilidade pode ser percebida em um sistema físico quando a mínima mudança em seus parâmetros (temperatura, carga elétrica...) ocorre. A menor perturbação gera uma poderosa mudança no funcionamento do sistema, capacitando sua transformação. Assim, podem ocorrer transformações irreversíveis resultantes de diferenças entre as energias potenciais.

Tal concepção não era possível na era clássica, quando apenas a estabilidade e a instabilidade, a regulação ou a ausência de regulação podiam ser concebidas. Os antigos não podiam conceber uma ordem que não fosse estável nem instável, nem ser nem nada.

Um sistema metaestável é sempre mais do que ele próprio, pois contém não só suas próprias potências quanto um potencial de auto transformação e mutação. São potenciais contrários, incompatíveis que requerem a criação de uma nova estrutura; o que torna o pré-individual capaz de produzir diferentes mecanismos de individuação. 
Um ponto central no pensamento de Simondon é considerar que o processo de individuação jamais termina: "Através das forças auto-organizadas do préindividual e da intrusão de um 'germe', modos provisórios de resolução no préindividual tornam-se possíveis e podem operar continuamente sem esgotar os recursos da atividade pré-individual”. ix 0 indivíduo vivo nunca está inteiramente acabado, individualizado, mas sempre em processo e em constante intercâmbio com o meio que o cerca. O vivo conserva em si uma atividade de individuação permanente. A diferença entre o vivo e a máquina é que ele não somente se adapta ao meio, ou seja, modificando sua relação com o meio, mas sim modificando a si mesmo, ao inventar estruturas internas novas.

Uma estrutura de elementos em interação, em conexão, muitas vezes instável, assim é a vida, viva. É possível estabelecer uma série de estados e ações que funcionam como relações de força. Esses estados e ações se engancham num entrelaçamento onde os polos não cessam de se incluir, de se superar, separar e finalmente se transformar.

\begin{tabular}{lr} 
Energia & Esgotamento \\
Guardar & Descartar \\
Deixar fluir & Estar em alerta \\
Distração & Integração \\
Luz & Escuridão \\
Leveza & Densidade \\
Intensidade & Inércia \\
Submissão & Subversão \\
\multicolumn{1}{c}{ Distante } & Próximo \\
Disjunção & Confluência \\
Intenso & Superficial \\
Contraditório & Compatível \\
Dobrar & Distender \\
Simetria & Desproporção
\end{tabular}





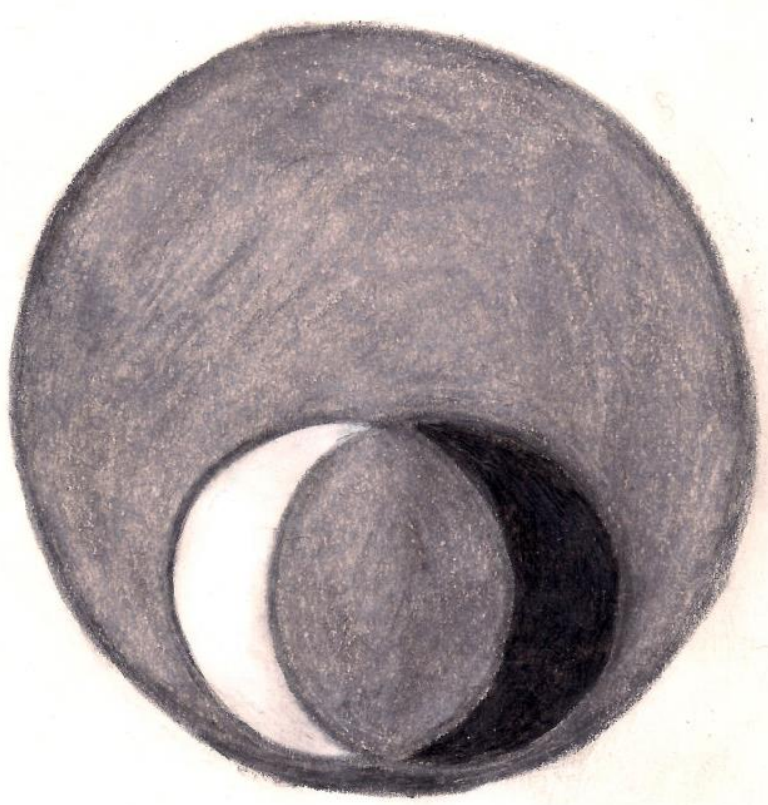

Perecível

Sobre o ponto de vista da criação artística, toda obra carrega algo de um estado de transformação, de impermanência, de perecível.

Obras antigas, por exemplo, são mantidas sob constante preservação e restauração, pois, sabemos que a estabilidade não é real, é só uma aparência, e as obras estão em constante troca com o meio externo.

Existe a possibilidade da deterioração física da obra pela troca com o meio e com as suas intempéries. A obra está passível a inúmeras condições deteriorantes, como 
mofo, umidade, radiação luminosa, e etc. Algumas esculturas situadas em ambientes externos sofrem de um efeito corrosivo em contato com a chuva ácida. É como se a água comesse a pedra, como se devorasse com mordidas o mármore e outras pedras calcárias, que estão lentamente destruindo e dissolvendo-se.

Essa condição perecível pode ser observada, ainda por exemplo, em um pentimentox. Os arrependimentos de Velázquez, como no Retrato equestre do Rei Philip IV de 1636 só se tornaram visíveis muitos anos após a execução do trabalho. As camadas superiores de tinta que foram adicionadas posteriormente pelo pintor, ganharam transparência ao longo dos anos e deixaram visível a 'versão' anterior das patas do cavalo. 0 quadro, ao expor duas imagens variantes, evidencia uma desordem ou subversão temporal, assim como seu estado de perpétua mudança.

Ambos os processos se dão em um tempo muito lento. Apesar de a vida da obra se sobrepor ao tempo de vida do artista, e o processo de transformação exigir uma temporalidade dificilmente observável, a obra se encontra nesse estado de perecibilidade.
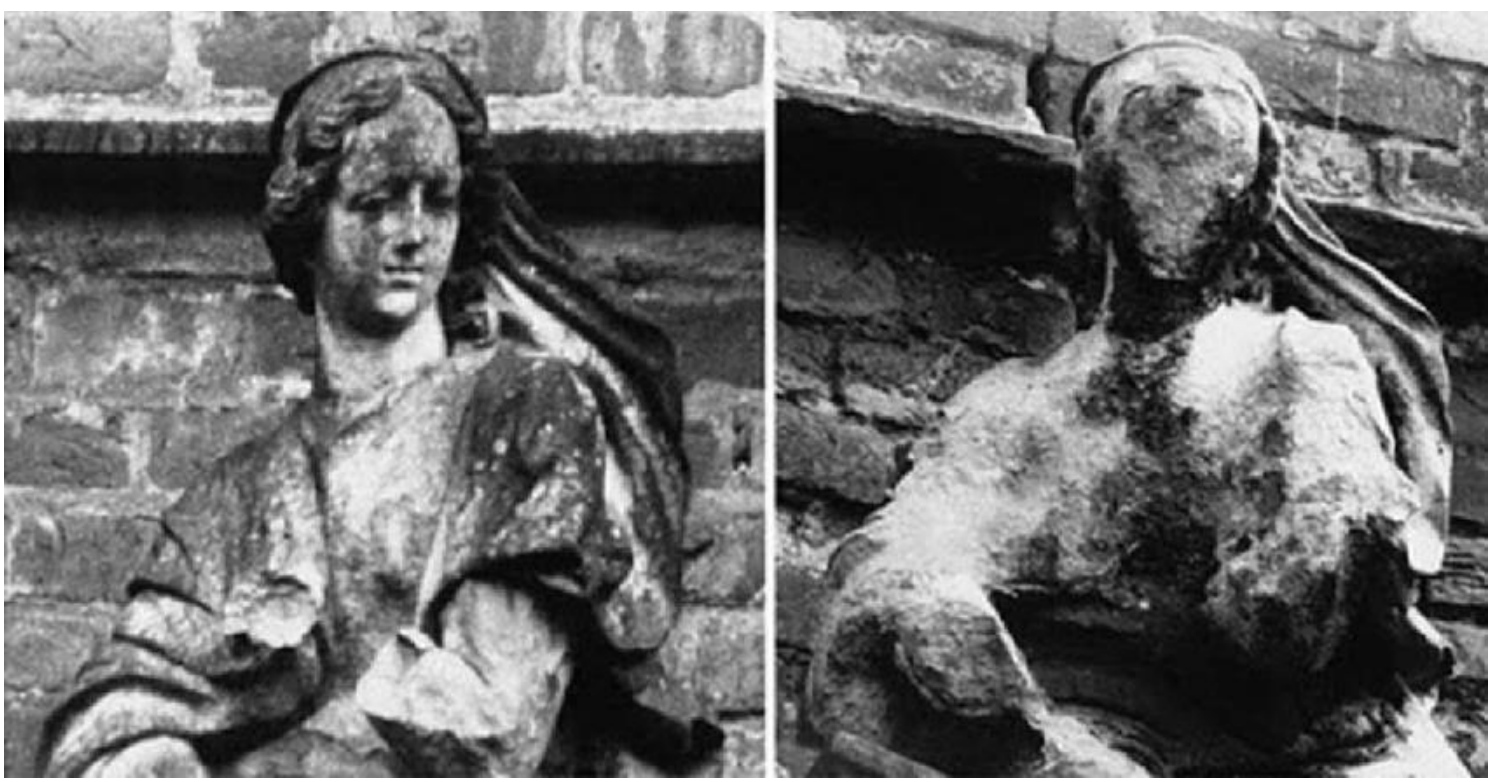

Escultura em Westphalia, Alemanha, fotografada em 1908 e em 1968, s.d. 


\section{Potencial energético = Potência da criação}

Existe uma outra dimensão do perecível e que podemos aproximar do estado metaestável de Simondon. 0 perecível não entendido no sentido de deterioração e finitude, mas sim a partir de sua origem etimológica, derivada do latim "perire": PER $=$ por, através + IRE = ir. "Ir através", é algo além do deixar de existir, que pode ultrapassar, transpor a morte de alguma forma. 0 perecível, nesse sentido, não é aquilo que somente acaba, mas é o que carrega a dimensão processual, carrega em si a energia potencial da criação.

\section{Tensão e potencialidade}

O que torna um trabalho perecível?

Em o Grande Buddha, de Nelson Felix as garras funcionam como disparador para um processo. 0 artista fixou seis garras de metal em torno de uma muda de mogno na floresta tropical no Acre. Na medida em que a árvore cresce, as garras penetram seu corpo. Especula-se que a árvore poderia viver aproximadamente 400 anos, sendo assim, ela seria capaz de absorver completamente as garras que desapareceriam no interior de seu tronco. A árvore, como todo vegetal e toda matéria viva, carrega a energia potencial capaz de operar a condição metaestável. 


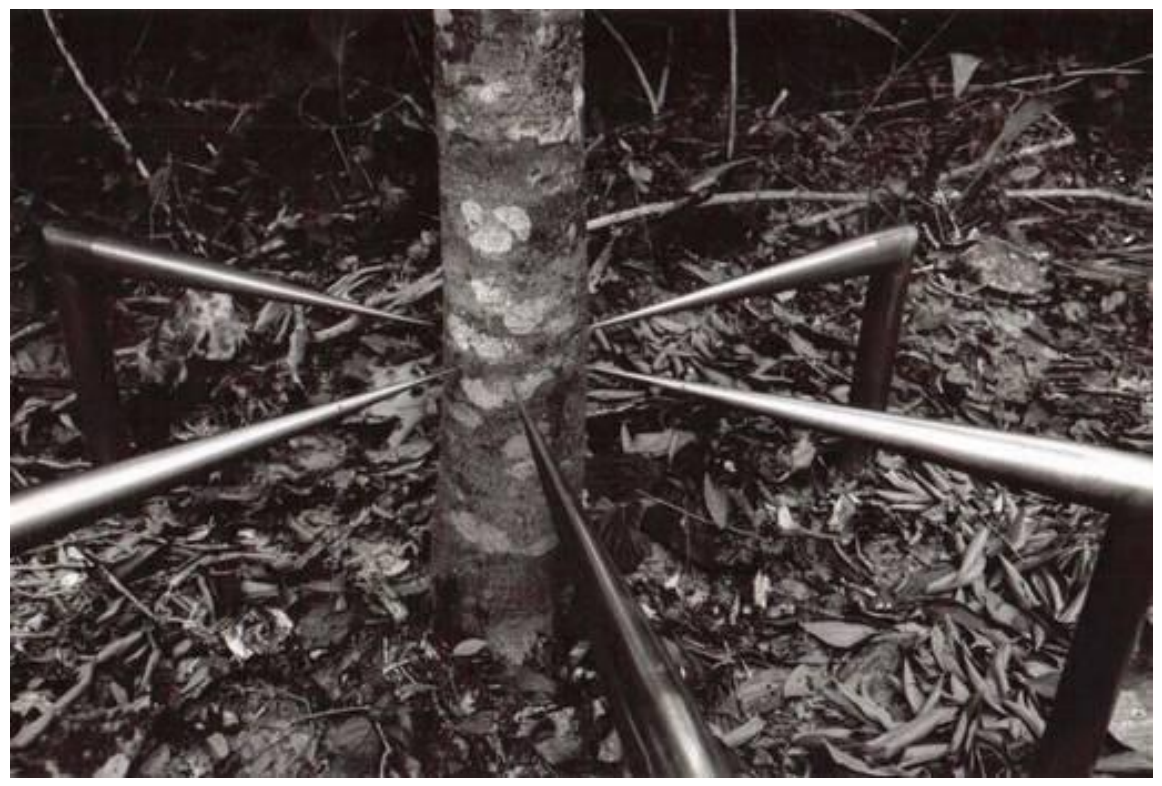

Nelson Felix, Grande Buddha, 1985

Com o trabalho de Felix podemos também recordar a definição de "corpo estranho" dada por Jean-Luc Nancy em Corpo Fora, que seria toda espécie de objeto, peça, pedaço ou substância introduzida de maneira mais ou menos fortuita no interior de um conjunto ou de um meio considerado homogêneo e dotado de uma regulação própria a qual o "corpo estranho" não se deixa submeter. Nancy usa como exemplo uma viga de cimento numa floresta e faz pensar então: o que seria então um corpo estranho numa construção? Seriam as gramas, musgos e árvores que crescem por entre muros ou fendas no concreto ultrapassando construções onde parece não haver terra alguma?

Artur Barrio, ao se deparar com um esgoto onde crescia erva viçosa e verdejante, escreveu em seu relato de 4 dias 4 noites: "da morte surgia a vida no processo incrível das transformações orgânicas, assim saquei a morte no sentido da vida ou seja que as duas formavam um todo neste pequeno planeta dito azul..."

Essas plantas parecem sobreviver numa condição aparentemente inóspita, de forma "independente" ou "autossuficiente", sem terra e somente com água proveniente de chuva, seu único sustento parece ser a luz sol. 
Para Emanuele Coccia as plantas encontram vida onde nenhum outro organismo consegue:

\begin{abstract}
As plantas não precisam da mediação de outros seres vivos para sobreviver. Nem a desejam. Tudo o que exigem é o mundo, a realidade em seus componentes mais elementares: pedras, água, ar, luz. Veem o mundo antes que ele seja habitado por formas de vida superiores, veem o real em suas formas mais ancestrais. Transformam tudo o que tocam em vida, fazem da matéria, do ar, da luz solar o que será para o resto dos seres vivos um espaço de habitação, um mundo. A autotrofia - é o nome dado a esse toque de Midas que permite transformar em alimento tudo o que se toca e tudo o que se é - não é simplesmente uma forma radical de autonomia alimentar, é sobretudo a capacidade que elas têm de transformar a energia solar dispersa pelo cosmos em corpo vivo, a matéria disforme e disparatada do mundo em realidade coerente, ordenada e unitária. (COCCIA, 2018. p.20)
\end{abstract}

Condição semelhante também acontece em Spiral Jetty de Robert Smithson. Em 1970, Smithson deslocou cerca de 6.000 toneladas de rocha de basalto negro e terra para formar uma espiral de 460 metros de comprimento e cerca de 4,5 metros de largura, no Great Salt Lake, em Utah. O lago foi escolhido pelo artista por suas propriedades ecológicas e geológicas incomuns, como a coloração avermelhada da água, causada pela alta presença de micróbios. A forma espiral reflete a estrutura molecular dos depósitos de sal de cristal encontrados em toda extensão do lago. Criado em uma época em que os níveis de água eram particularmente baixos, o Spiral Jetty foi submerso em 1972. As secas causaram a recessão do lago em 2002 e a escultura permaneceu visível desde então. Os níveis de água flutuantes e a salinidade da água remetem ao conceito de entropia sempre colocado pelo artista.

Toda a obra de Smithson perpassa a condição dos materiais, evidenciando o processo de formação, sua estruturação, sedimentação, ação geológica e industrial sofrida pela matéria e que acabam por moldar uma paisagem. 0 artista produz uma série de possíveis ações como suspender, inclinar e deixar cair, usando a tendência do próprio material e criando a partir de seus processos inerentes. Tudo se coloca sob o princípio da matéria conduzida por dinâmicas irreversíveis, sejam processos industriais, disrupção urbana e ambiental ou fenômenos naturais como estratificações minerais, formações geológicas e cristalização. Assim, processos 
como gravitação e sedimentação adquirem função operatória, como agente no processo artístico.

Na obra Sun Tunnels, de Nancy Holt, os furos projetam no interior dos túneis escuros um conjunto de pontos de luz solar que estão sempre em movimento com a transitoriedade da luz do sol. 0 trabalho foi construído em 1976 no deserto de Utah, com quatro cilindros de concreto dispostos em forma de cruz num espaço de 26 metros de largura. Os eixos dos túneis se alinham no solstício de verão e inverno, de modo que cada túnel 'reage' de maneira diferente à luz natural; nos solstícios, os túneis enquadram o sol ao passar o horizonte no nascer e pôr do sol. Uma série de furos perfura cada cilindro que variam em tamanho de acordo com a magnitude das estrelas que representam. Holt projetou os padrões dos furos correspondendo a quatro constelações celestes. Utilizando a luz como material, uma luz que é transitória, que cria sombras e que principalmente varia de intensidade, a obra opera um movimento cíclico, lidando com as intempéries, mas logo se realinhando e retornando a forma como foi concebido.

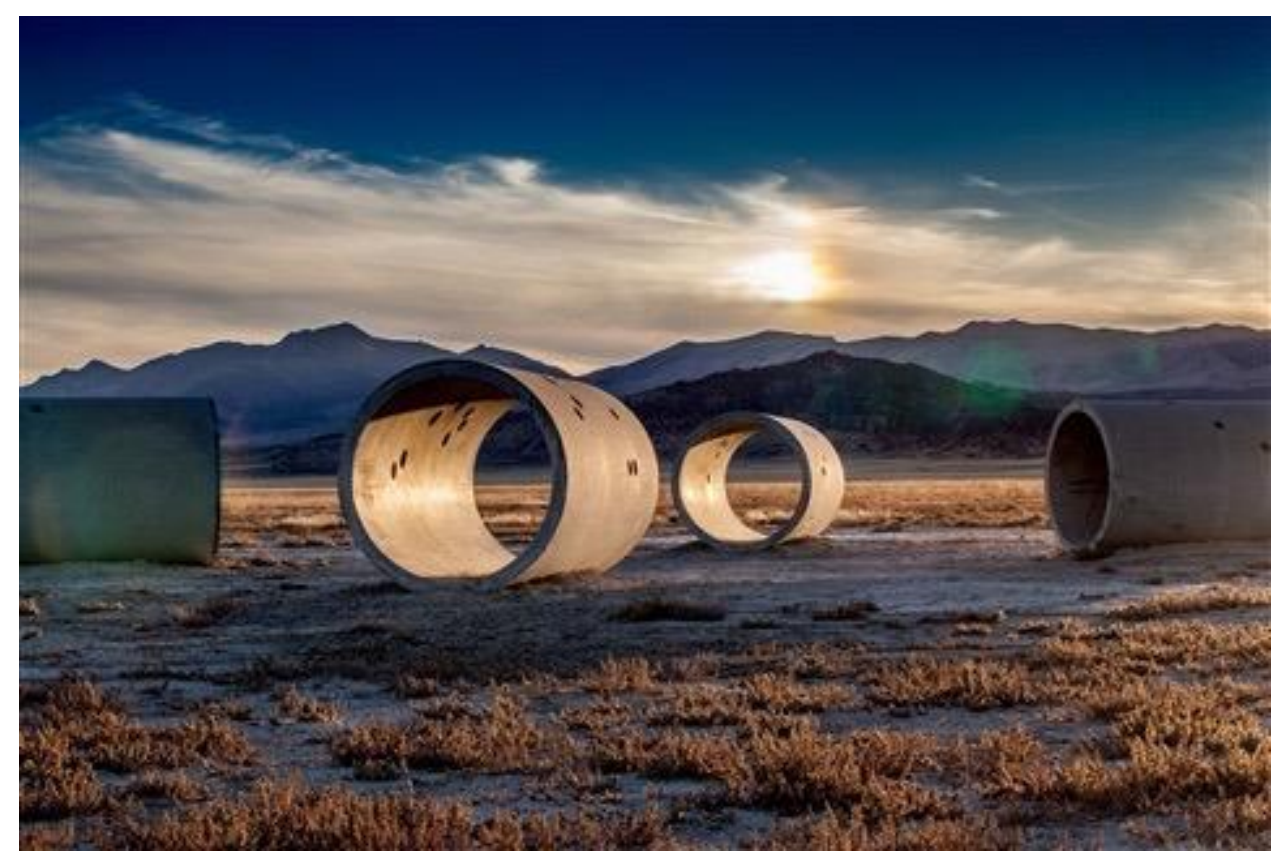

Nancy Holt, sun tunnels, 1976 
A metaestabilidade proporciona um fluxo constante entre um estado de equilíbrio e desequilíbrio e um realinhamento de estruturas. Na arte, o perecível está sempre numa condição de tensão e potencialidade.

\footnotetext{
${ }^{\mathrm{i}}$ HERÁCLITO, fragmento DK22 B12

ii Tornar a nascer se refere ao conceito de metempsicose - movimento cíclico por meio do qual um mesmo espírito, após a morte do antigo corpo em que habitava, retorna à existência material, animando sucessivamente a estrutura física de vegetais, animais ou seres humanos; reencarnação. Trata-se de uma crença amplamente difundida na pré-história e na antiguidade, sendo encontrada entre os egípcios, gregos, romanos, chineses e indianos.

iii GONÇALVES, 2006, p.8

iv Ibid. p.12

v Gilbert Simondon (2 de outubro de 1924 - 7 de fevereiro de 1989) foi um filósofo francês mais conhecido por sua teoria da individuação, uma importante fonte de inspiração para autores como Gilles Deleuze e Bernard Stiegler.

vi A principal obra de Simondon se chama justamente $A$ individuação à luz das noções de forma $e$ informação.

vii GROSZ, 2017, p. 173

viii Ibid, p.174

ix GROSZ, 2017, p. 174

x "Pentimento" em uma pintura é uma alteração encoberta pela versão final de um quadro e que aparece com o passar do tempo. Pentimento vem do italiano pentimenti que significa arrependimento.
}

\section{Bibliografia}

COCCIA, Emanuele. A vida das plantas: uma metafísica da mistura. Florianópolis: Cultura e barbárie, 2018

GONÇALVES, Márcia. Filosofia da natureza. Rio de Janeiro: Jorge Zahar Editor, 2006.

GROSZ, E. A. The incorporeal : ontology, ethics, and the limits of materialism. New York: Columbia University Press, 2017.

NANCY, Jean-Luc. Corpo Fora. Rio de Janeiro: 7 Letras, 2015.

NAVES, Rodrigo. Nelson Felix. São Paulo: Cosac \& Naify, 1998. 
PEIXOTO, Nelson B. Paisagens críticas Robert Smithson ; arte, ciência e indústria. São Paulo: EDUC, 2010.

PONTY, Maurice. A natureza. São Paulo: Martins Fontes, 2006.

SMITHSON, Robert. Entropia e os novos monumentos, 1966.

WOHLLEBEN, Peter. A vida secreta das árvores. Rio de Janeiro, RJ: Sextante, 2017.

Recebido em: 15/11/2018

Aprovado em: 17/11/2018 